Article

\title{
New Perspectives for BIM Usage in Transportation Infrastructure Projects
}

\author{
Ángela Moreno Bazán ${ }^{1}$, Marcos G. Alberti ${ }^{2, *}$, Antonio Arcos Álvarez ${ }^{1}$ (D) and \\ Jesús Alonso Trigueros ${ }^{1}$ \\ 1 Departamento de Ingeniería y Morfología del Terreno, E.T.S de Ingenieros de Caminos, Canales y Puertos, \\ Universidad Politécnica de Madrid, 28040 Madrid, Spain; angela.moreno@upm.es (Á.M.B.); \\ antonio.arcos@upm.es (A.A.Á.); chus.alonso@upm.es (J.A.T.) \\ 2 Departamento de Ingeniería Civil: Construcción, E.T.S de Ingenieros de Caminos, Canales y Puertos, \\ Universidad Politécnica de Madrid, 28040 Madrid, Spain \\ * Correspondence: marcos.garcia@upm.es; Tel.: +34-91-0674121
}

Received: 11 August 2020; Accepted: 9 October 2020; Published: 12 October 2020

\begin{abstract}
Although there is already a great amount of scientific literature dealing with the use of building information modeling (BIM) in engineering activities, the majority refer to successful case studies using the usual methods and technology of building construction but rarely bring up the real problems for implementing BIM methodology to the field of transportation infrastructure. It must be also considered that the construction activity is only a part of the infrastructure life and the stakeholder must consider the works of enlargement, renewal, and maintenance of the infrastructure. The purpose of this paper is not only to show a mere review of the existing literature but also present a rational analysis for the use of BIM in different areas of civil engineering. For that purpose, the gathered experience in the use of BIM in civil engineering projects in the final course of Civil Engineering Master Studies in the Civil Engineering School (ETSICCP) at Universidad Politécnica de Madrid were compared with the reported literature. This way, a complete and updated information regarding tendencies, applications, and practice along with limitations and benefits can be presented. The significance of this research relies on the original insight of BIM for civil engineering applications through four case studies. Two of them were focused on construction possibilities and the other two on the possibilities in the exploitation, rehabilitation, and maintenance. The results showed that despite the lack of previous experiences, the use of BIM methodology is possible for activities such as maintenance, managing, or expansion of infrastructure by applying different specific software packages. Among the main problems needing to be addressed are the following: handling of big data files, the integration of new data non-related with the modeled object, and interchange of data without losing information. That proves the need of new more efficient techniques to overcome the challenge of the full use of BIM in the civil engineering field and obtain the mutual advantage of the co-operation of the academic and industrial worlds.
\end{abstract}

Keywords: building information modeling BIM; BIM infrastructure; BIM data management; facility management; monitoring systems

\section{Introduction}

The building information modeling (BIM) approach considered as a series of technologies and methodology procedures is currently becoming a standard for developing projects worldwide [1,2]. In this context, most corporations have assumed that the professionals have not acquired enough contents and competences in BIM methods along their university studies although they have got enough basic instruction as to overcome this lack of skills [3]. One of the main problems is the lack of education 
of the professionals and the teaching personnel [4] and that is why this kind of formation has been expanded and increased in the postgraduate studies, mainly in the fields of architectural and building construction, but also, in recent years, in the civil engineering field [5]. The successful use of BIM in the building construction projects proving the advantages of its implementation implies that, with some perspective changes, it can also be used in infrastructure projects, including linear projects [6].

The main subject to be taken into account for using BIM in infrastructure projects such a hydraulic works, roads, railways, complex structures, complex foundations, and even historic restoration works is that these projects have different characteristics compared with architectural works and the BIM application should be resolved by the use of specific solutions and tools. That must start with the application of scales consistent with the level of development (LOD) of the project that in turn should be coherent with the definition or detail level of the project development (see Figure 1).

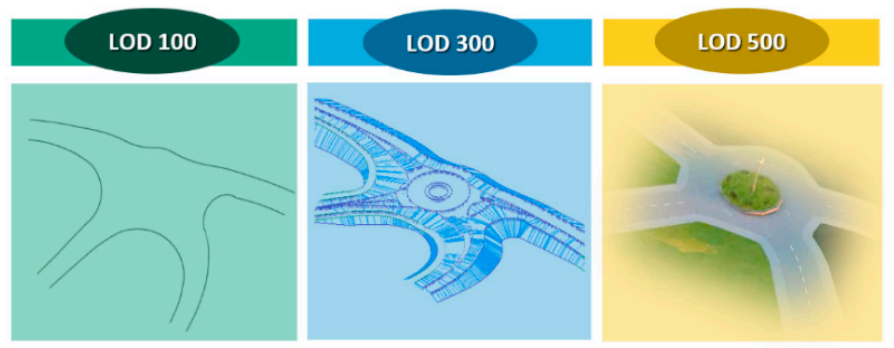

Figure 1. Level of development of a traffic roundabout.

In recent years there have been an important impulse to the development and practice of innovative technologies in construction projects. The universities are not unaware of this reality and have included formation in BIM in order to improve the professional opportunities of their alumni [7]. BIM methodology comes from the construction industry and is an approach that allows the visualization of the design-simulated project [8] providing the overall understanding of the functionality and operability of all integrated elements. It is an opportunity of developing not only the 3D model but also the creation of a collaborative and centralized information system. The aim of BIM is to capture all information and aspects of the project so that it can be further utilized in the operation and maintenance activities.

Figure 2 shows some examples of BIM models that include the geometry of the building, the spatial relationships, and the geographical information along with the quantities and properties of the components. A common tool for a BIM approach is Autodesk Revit. This tool is normally used to create highly visual models and is already of common use in building construction.

However, while the BIM application to architecture, construction, and manufacturing activities has been widely adopted, it has gained scarce application in transportation engineering. The tempting efforts have been so far insufficient and currently problems still exist for its implementation. At present the use of BIM in the civil engineering field is focused in the application of BIM tools in terms of working methodology, the integration of the gathered information and the data inter-relation and the transfer to third parties. However, the adaptation to structures like bridges and roads is a much more complex process.

The purpose of this work is to provide a critical analysis of the use and application of BIM in different civil infrastructure works, identify gaps, and propose solutions to obtain the maximum profit of the technology and computer applications so far utilized in the construction industry. Published literature related to BIM has mainly focused on buildings and there is a lack of clear possibilities and tendencies to be used in civil engineering even though it is mandatory in many countries. The significance of this research relies on the original insight of BIM for civil engineering applications through four case studies. Two of them were focused on construction possibilities (one bridge and one road) and the other two on the possibilities in the exploitation, rehabilitation, and maintenance (one bridge and one road). Those projects were developed with advanced BIM technologies that 
have shown that the use of BIM in infrastructure projects not only clarifies the main objectives of the project making it more visible, but also reduce the risk of errors, ease the possibility of studying more alternatives and help the decision-making process for the management staff. In addition, it can help to register and maintain all the historical actuation on the infrastructure through the use of databases linked to the model. This can be of great importance for the future public facility management (FM) and rehabilitation of bridges that are counted in hundreds of thousands in Europe and developed countries older than 50 years.

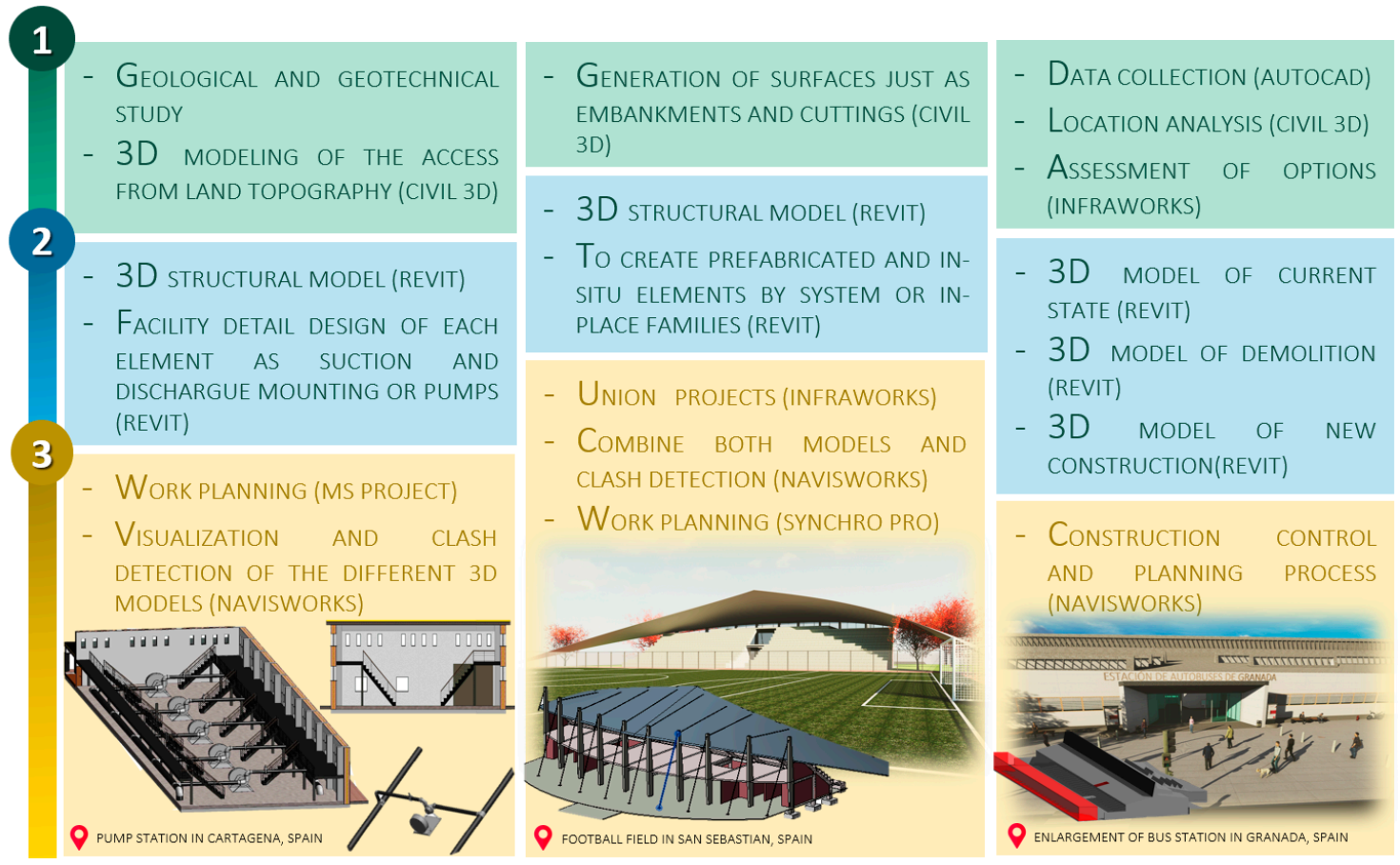

Figure 2. Example of a design by building information modeling (BIM) methodology.

\section{Materials and Methods}

The main purpose of this study implied the use of a significant diversity of software and equipment. For each of the case studies, the methods and technology required were different. In order to develop each project, the methodology had to be carefully studied, in addition to organize the participation of the different academics with expertise in each topic as well as the contribution of students. This process was based on an initial technical characterization of the four projects. The participants in this experiment included a group of civil engineers with an average experience of fifteen years of experience. For these four studies, all the computing resources and access to all Autodesk (Autodesk, Inc., San Rafael, CA, USA) and Bentley (Bentley Systems, Incorporated, Exton, PA, USA) commercial software were available. In addition, other software of great interest such as Dynamo, SketchUP, Revizto, Rhinoceros, and Grasshopper, required for the correct execution of the modeling, were also available.

The projects were divided into two main sections: bridges and roads. In the case of bridges, as a first objective, the detailed procedure of the virtual construction of three-dimensional bridge models following BIM methodology was chosen. Further perspectives were defined for each of the case studies.

The first case study introduced and implemented the developed framework for the maintenance and exploitation of bridges. It was based on the possibilities of Dynamo. In addition to this, the main data for the conventional maintenance of bridges was used to reach the main objective of the project. Object-based parametric modeling is one of the bases of BIM technology, and Dynamo can be used to bring procedural information into the BIM environment. In this case of study, Dynamo enabled the communication between the worksheet samples from the government and the model. The second 
case of study aimed to develop a methodology to design different rehabilitation alternatives. After an extensive literature review, this project proposed a BIM-based rehabilitation of a bridge over the Perales river using project management software.

The second section shows the other two case studies performed with the aim of showing new perspectives of BIM applied to linear works, specifically to roads, tunnels, and highways. Thus, the third case study shows the procedure developed based on parametric BIM generation with 3D scanning through use of drones. In this case, a drone model Mavic-Pro M1P was used. The process was divided into three parts: (1) data acquisition with ContextCapture, (2) geometry information extraction in OpenRoads ConceptStation, and (3) parametric BIM modeling in SketchUP. The purpose of this work was the acquisition of information for the management of the road, the building of a virtual information model, and assessing both the costs of implementing this methodology per kilometer and its suitability. The fourth case study introduces a BIM framework, which could effectively integrate the assessment of optimized linear designs based on road traffic and risk. For this study, an indicator of risk (IRDO) based on hierarchical-analytical criteria was designed as well as a Hasse diagram with the most important attributes. For the detailed elements SketchUp was used. Various alternatives were generated using OpenRoads ConceptStation.

\section{Results}

\subsection{Bridges}

In recent years, the big worldwide development of transportation has given rise to the construction of a very large number of bridges. Bridges play an important role in the transportation system giving support in the social and economic development and, therefore, are very important and indispensable infrastructure elements. The earliest research work encountered in the BIM bibliography on transportation infrastructure is the development of a microcomputational system for bridge management. Although bridges and buildings may appear similar and have similar characteristics, they are quite different in terms of construction, operation, and element classification [9].

According to official statistics Spain has a road network of 165,624 km and more than 100,000 bridges. From those, about 25,000 bridges are managed by the government and, given the age of many of them, only $6.5 \%$ do not present anomalies of any issue [10]. In addition to this, other bridges such as those of the train system or footbridges must be added as well as those managed by the regional governments and local authorities. The economic value of their new construction has an estimated cost of 12,000 million euros [11]. This gives an idea of the magnitude of the required maintenance and structural management activities. Here is where the BIM technology can develop an efficient management and maintenance system for bridges [12], which in turn will improve traffic safety. For that goal, a standard method for structural modeling is required. With it the bridge modeling will be easily completed with all the pertinent information. If the information relative to the foreseen actions to be taken in the bridge service life time, for example alerts to specific revisions and maintenance actions, the system will allow extending the life expectancy of the bridge and provide a planned schedule for future payments, so improving the project cost control. It is necessary to create a standard of collaborative bridge maintenance containing information of the past, present, and future status of the bridge.

As MacLeamy [13] states, for each dollar invested in the project phase twenty dollars are invested in the construction phase and 70 or more along the infrastructure lifetime. Thus, BIM means big public funds savings in cost overruns that can reach $40 \%$ according to the survey reported by Stanford University [14] and in maintenance and management costs.

In order to obtain a scheduled planning of a bridge service life, the bridge information model or BrIM must be built up during the design and construction stages [15]. However, most of the existing bridges were designed and constructed without contributing to the modeling. Therefore, the model must be reconstructed for most of the bridges. In this section some successful case studies of standard 
modeling software packages are presented that can be further used to elaborate plans for the bridge service life.

The most important criteria in the design and construction phases refer to the level of development (LOD) and the level of information (LOI). In building construction LOD is directly related to internal specifications but in civil infrastructure the focus is on external specifications including geometry details and semantic information [16]. In fact, bridges have some unique characteristics such as road alignment or beam slopes that are of most importance in the design, construction, and fabrication of the bridge. An important number of publications $[17,18]$ suggest methods to achieve substantial improvements in the design process, a sharp reduction of conflicts and even industrial benefits through use of BrIM. However, currently LOD faces an important challenge in infrastructure elements like bridges [19]. Due to the high amount of work involved in the bridge modeling it is necessary to unify the basic information prior to the model setup [20]. In Figure 3 some examples of BrIM realized with different methodologies and with a high LOD level (LOD 300-400) are described.

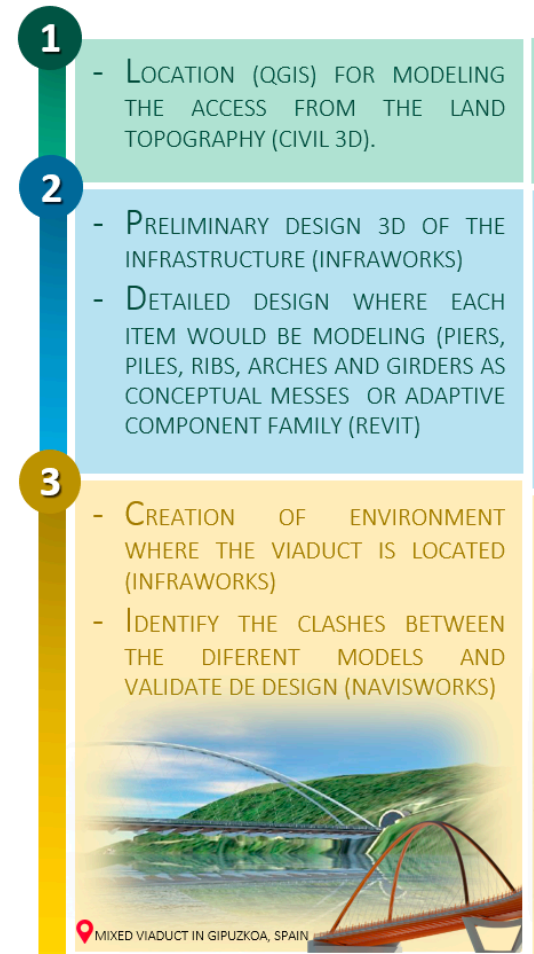

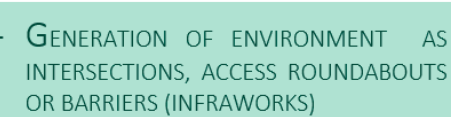
OR BARRIERS (INFRAWORKS)

- First attempt at modeling With BASICS PARAMETERS AS ABUTMENT OR PAVEMENT(INFRAWORKS)

- To cREATE A CONCEPTUAL MESSES FoR THE BOX, GANTRIES AND ARCHES (ACAD 3D)

MOdeling THE DECKING AND OTHERS SINGULAR ELEMENTS (REVIT)

\section{UnIFY THE TEXTURES (INFRAWORKS)}

COMBINING BOTH MODELS, CREATING THE CONSTRUCTION PROCESS AND CLASH DETECTION (NAVISWORKS)

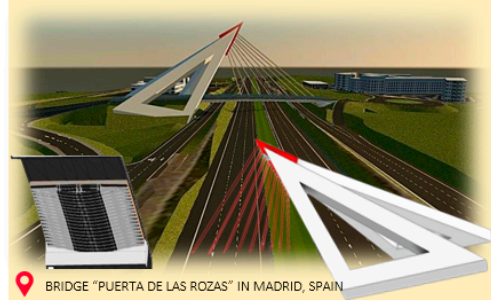

- To OBTAIN THE LEVEL CURVES (QGIS)

TO GENERATE THE GROUND LEVEL, WALKWAY TOP, ABUTMENTS AND PILES LOCALIZATION AND AUXILIARY VOLUMES (CIVIL 3D)

THE ENVIRONMENT ASSEMBLY (INFRAWORKS)

TO CREATE THE DECKING AND ACCESS RAMPS WITH FAMILIES (REVIT). MASS METRIC FOR PILES, ABUTMENTS AND POLES. METRIC PROFILE-HOSTED FOR DECKING, IMPOSTS OR KERBS. ADAPTATIVE PROFILE FOR TIES AND RAILS.

UNIFY WALKWAY AND ENVIRONMENT (INFRAWORKS)

- To associate an editable tablet (EXCEL) WITH THE 3D MODEL

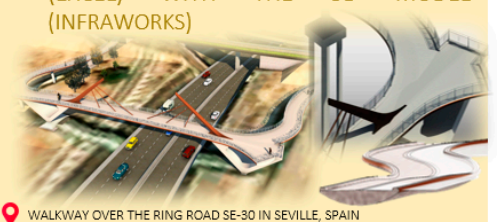

Figure 3. Example of a design methodology by a bridge information model (BrIM).

The working sequences shown try to show how by combining different software packages the correct completion of a BrIM model system can be achieved. In the initial phase, the use of tools like Infraworks or Civil3D allows the inclusion of data for the different configuration alternatives and the definition of the basic parameters to be further exported to Revit for the design completion. If both packages are used for the surroundings and access it must be taken into account that importing Civil3D to Infraworks runs perfectly but the inverse process is quite problematic. For a second phase, Infraworks infrastructure modeling can also be used although the most elaborate elements such as hangers and ribs of the bridge must be previously created as parametric elements using Inventor or Rhino. The problem appears when these structural elements are exported because neither Revit nor Navisworks detect their area or volume and so they are not quantifiable. For this reason, at least until this problem is resolved, modeling software such as Revit needs to be directly used for the detailing design of the infrastructure although this requires the creation or modification of a number of families, because such software type is rather limited for highly complex geometries. This can be resolved utilizing "conceptual masses" by previous modeling in Civil3D, AutoCAD3D, or Inventory 
(all Autodesk, Inc., San Rafael, CA, USA) making a family able to create a dotted Spline in Revit whose area and volume parameters can be assigned. In a final phase, the most useful software to combine the models is managing software such as Navisworks, though the textures and georeferences sometimes may cause problems. It is also possible to combine them in Infraworks but in that case the Revit model must be created as a 3D object.

Then, as shown in Figure 4 and following this procedure it is possible to create a virtual and intelligent 3D model of the bridge containing all pertinent information for each component and for the whole service life.

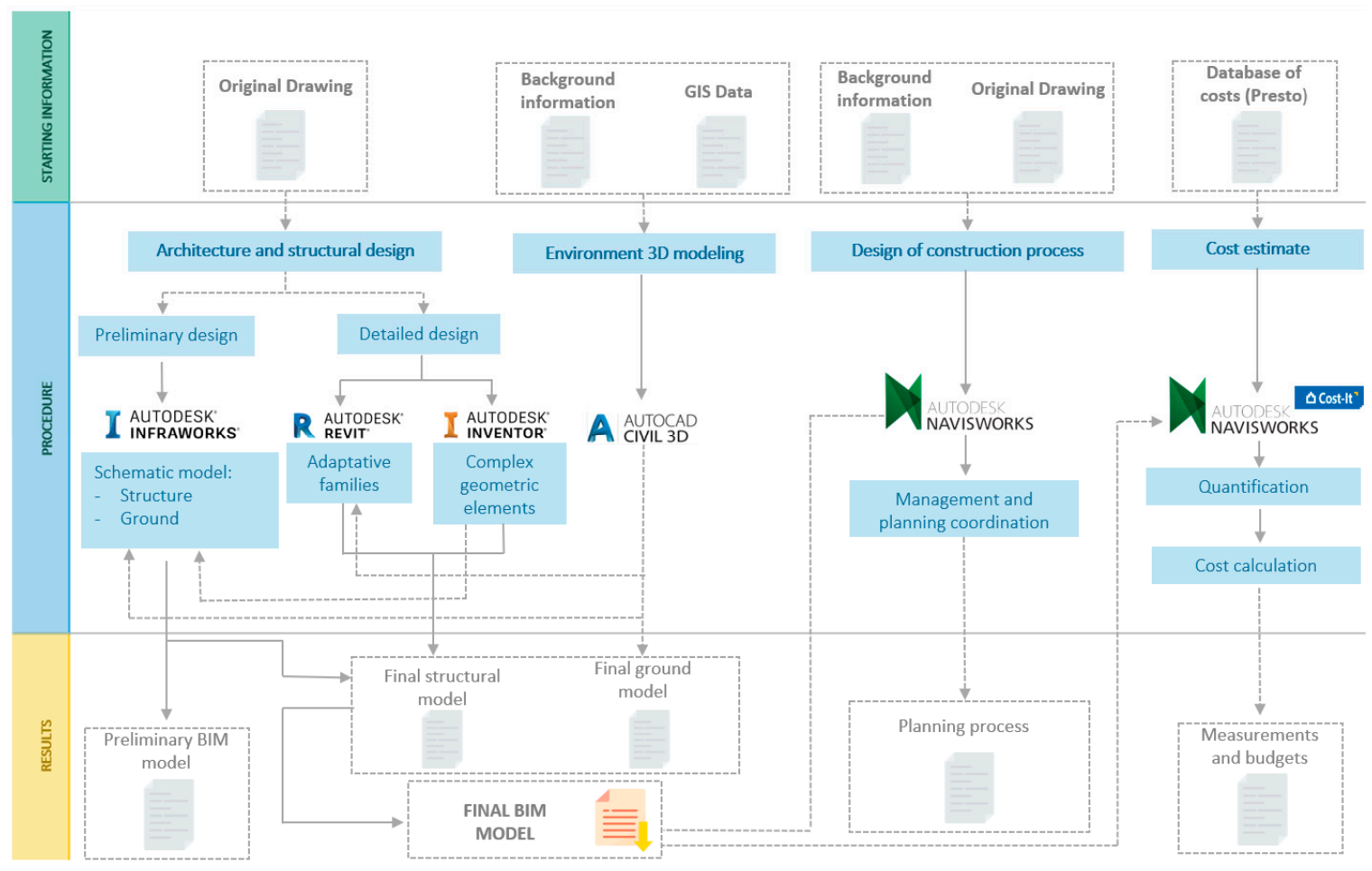

Figure 4. Proposed facility management workflow for BrIM.

In Europe, there is a bridge management system (BMS) that provides support to the design, construction, operation, and maintenance phases. This BMS improves the efficiency and cost control of the infrastructure management problems. The countries investing most in this system are Finland, Denmark, and Germany [21]. Nevertheless, the system still holds some drawbacks [12].

Although BIM has been implemented in the stages of design and construction of many bridges, as commented above, the application to the stage of maintenance has started relatively late [22]. In Spain, the BIM based management of the bridge service life is still under development. Additionally, as other countries, the tendency is combining BIM with the traditional managing methods to improve the management efficiency [23].

\subsubsection{Case Study 1}

With the large amount of Spanish bridge inventory, the maintenance becomes an important and challenging task. Additionally, that makes a BMS system a useful and essential tool. In fact, recently, the government awarded a contract of an urgent inspection of 2500 flyover bridges by the amount of 18.12 million euros. Due to this, a BIM model in the near future would be necessary, at least in new constructions. With these new data in the model, any incidence detected in successive inspections along the bridge service life will be incorporated to the design model. Thus, by making use of the data contained in the model [24] it would be possible to get a cost estimation of the repairing works recorded in the inspection. 
The BIM methodology has been proposed to incorporate the bridge inspection to a BIM model. A flyover bridge (Figure 5) was selected because of the great similitude of elements and typology with many other bridges and because of the design simplicity that would allow extending the model to other bridges with scarce modifications.

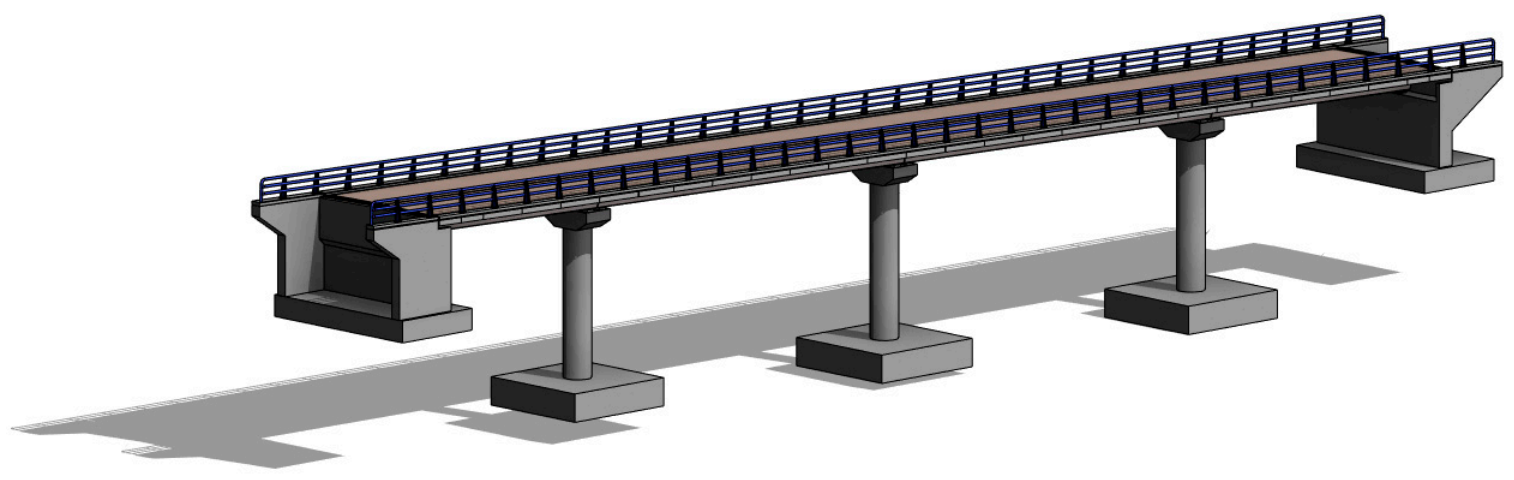

Figure 5. Flyover bridge in the AP-41 highway.

A complete information model of a bridge was performed as a reference. Previously, LOD were defined in order to gather all the information of the traditional project and drawings. Thus, the components of the structure were defined and virtually created and constructed. Following the rationale of any construction task, every structural component was considered (neoprene bearings, footings, abutments, girders and prefabricated elements, decks, expansion joints, etc.). However, on-site maintenance inspections can reveal pathologies associated to groups of elements such as spans or abutments. These options were not preconfigured, and new families were created to group the components in the following:

- Abutments with their respective foundations.

- $\quad$ Piers and pile caps with their respective foundation.

- Spans.

- Support lines and leveling.

- Parapets.

The main purpose was to establish a connection between the basic inspection sheets (BISs) in Excel currently used by the Ministry of Civil Works and the BIM model. The management data was developed and is shown in Figure 6.

The flyover bridge management system must:

(1) Classify the potential pathologies by categories, assign an ID, and prepare a digital format sheet (Microsoft Excel) for inspection adjoining a base of unit prices to assess the repairing cost of each pathology (BIS). Additionally, the 3D structure must be modeled (Autodesk Revit and Autodesk Civil 3D) with the pertinent parameters for the damage statement as a BIS function.

(2) Link up the BIS incorporating the field information with the structure. For that purpose, a programming code in Dynamo must be created that is to be repeated for each possible damage in each structural element, as can be seen in Figure 7.

a. Information import in Autodesk Revit. Each element family must be placed in a different Excel sheet to facilitate the Dynamo programming language.

b. Export the information to Microsoft Excel.

(3) Graphic visualization of the 3D structure status along with an estimation of the repairing costs according to the reported damage (Figure 8). This computerized data can be saved and analyzed from different points of view: 
a. Technically: some pathologies occurring with excessive frequency can be detected and an alternative solution may be proposed.

b. Economically: costs of successive campaigns can be compared, and future costs can be estimated, so optimizing resources.

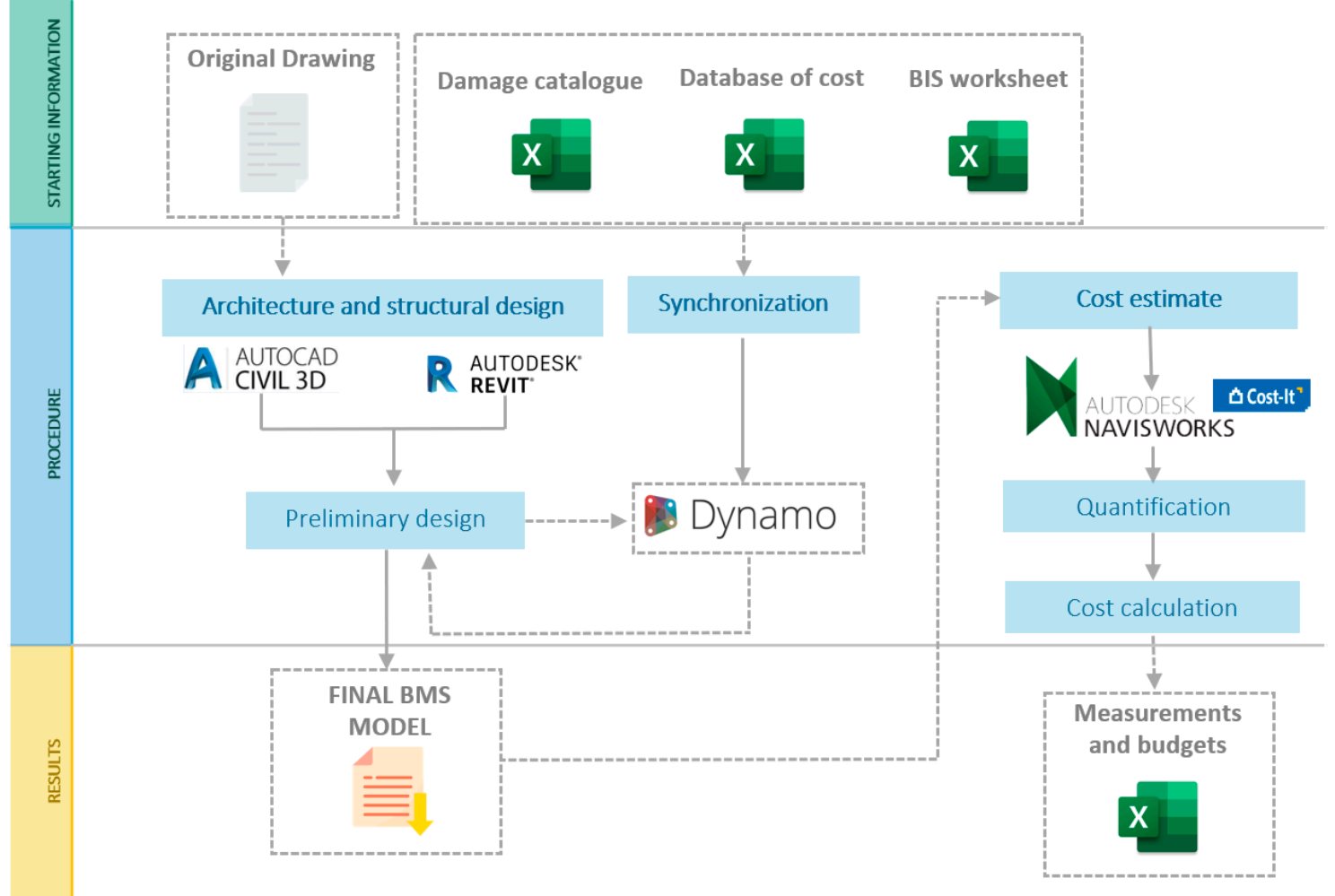

Figure 6. Proposed facility management scheme of BrIM maintenance.

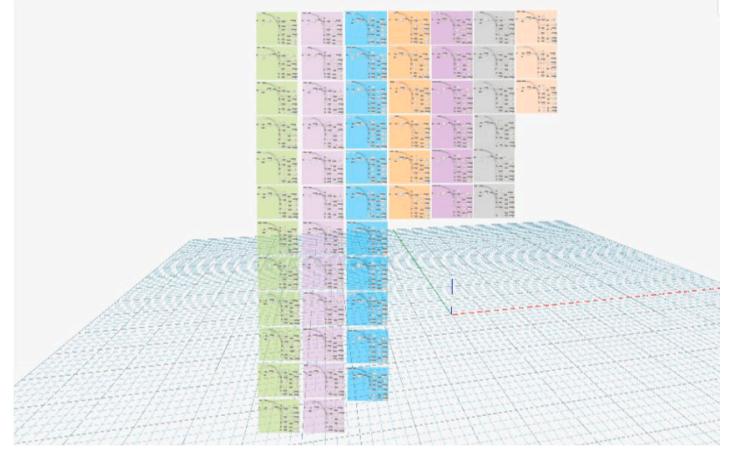

(a)

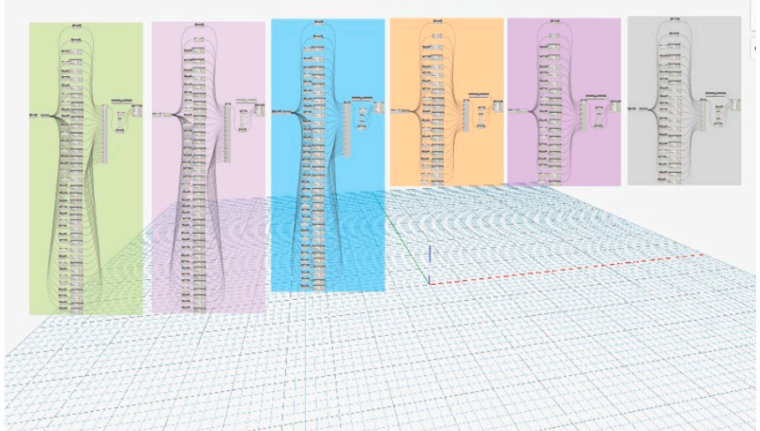

(b)

Figure 7. (a) Importing in Autodesk Revit the Microsoft Excel information and (b) exporting the Autodesk Revit to Microsoft Excel. 

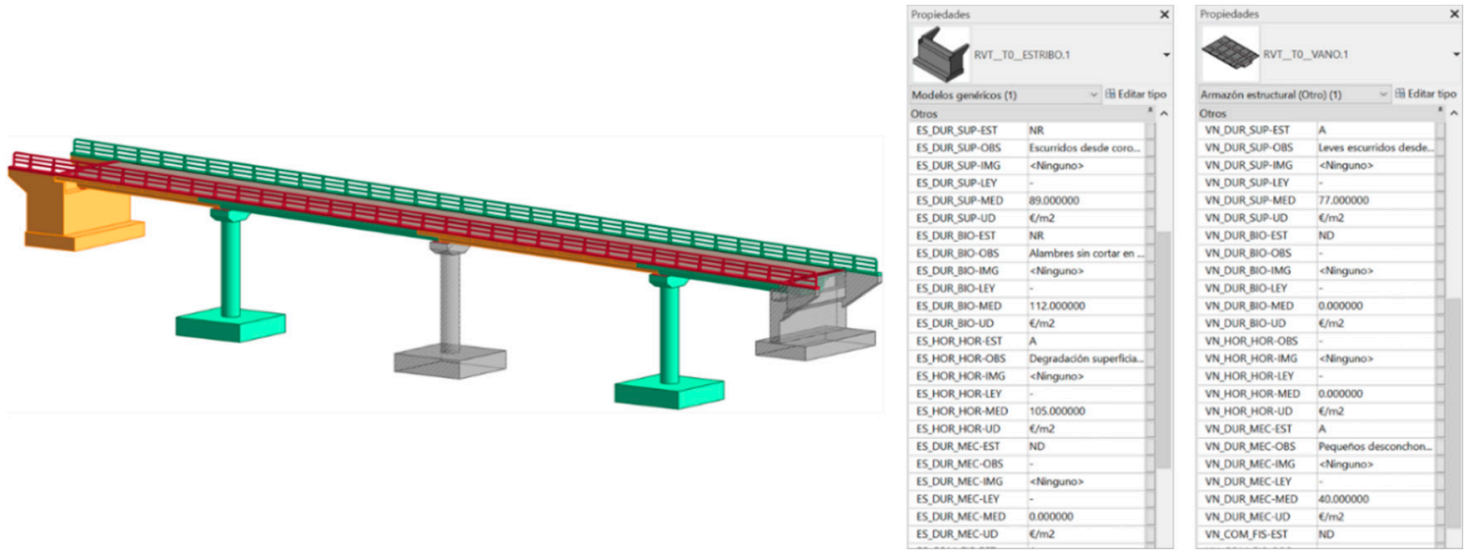

Figure 8. Graphical visualization of the bridge management system (BMS).

Given the large number of parameters to be introduced to each of the modeled elements, an extensive code was developed. The groups generated in the code permitted treating damages as a parameter affecting all the elements that belong to a family. Figure 9 shows detail with a simplified view of how this import was programmed.

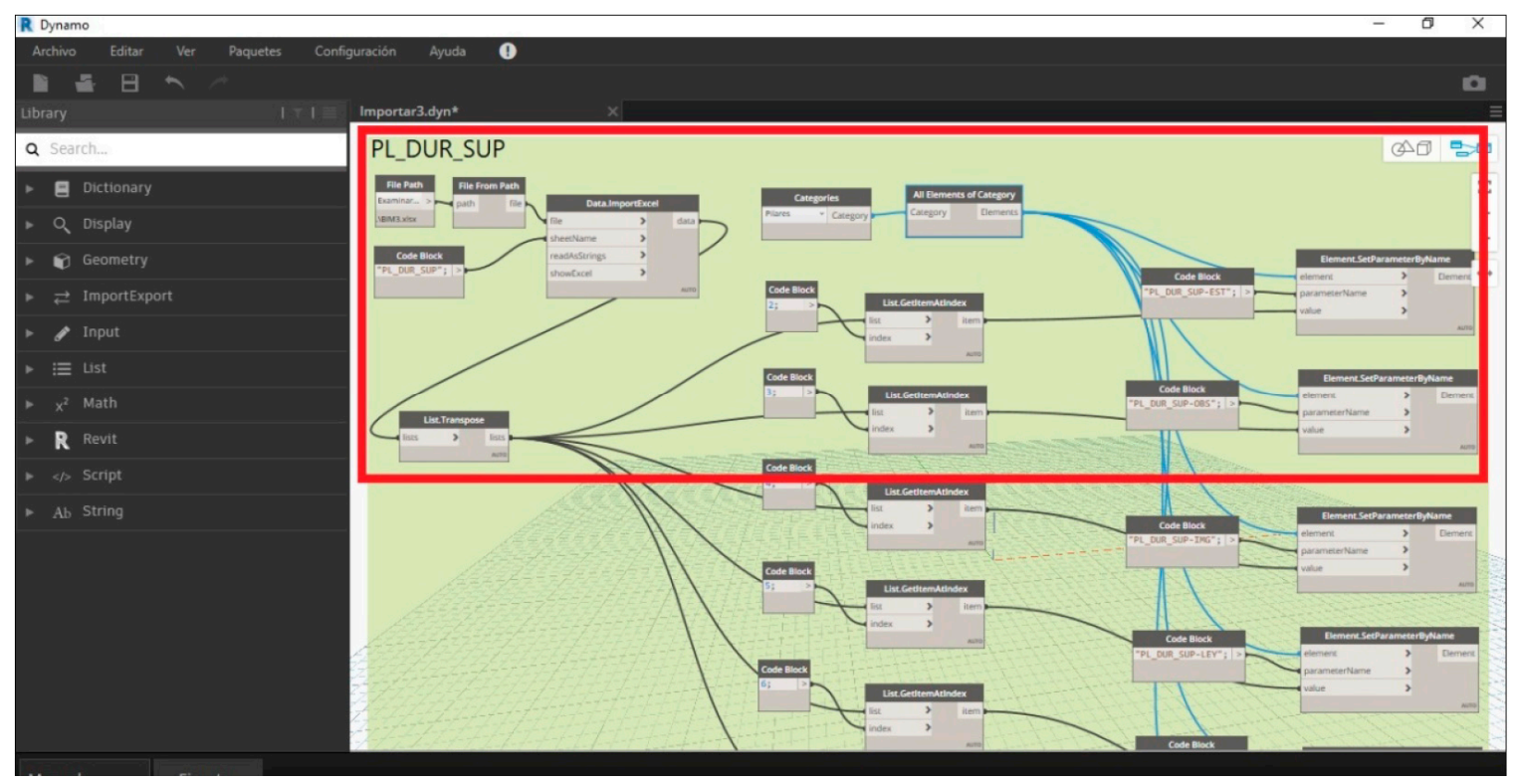

Figure 9. Detail of the import code for damage with id PL_DUR_SUP.

In Figure 9, two main functions have been highlighted given their relevance:

(1) Data.ImportExcel: extracts cell from a certain worksheet. The information read from the worksheet will be gathered in lists through the command List.GetItemAtIndex.

(2) Element.SetParameterByName: the lists of elements read in the adequate position (through use of the List.Transpose command) will be incorporated to the element parameter of a category by means of this function.

This way, damage PL_DUR_SUP of each of the piers of the Pier category is added to the previously created parameter. The same procedure was carried out in order to incorporate the rest of the parameters to be introduced in the model (piers, abutments, spans, bearings, dilatation joints, or parapets).

The main objectives of the project included not only to generate an information model but also to enable the information of this model to be used for the maintenance of the bridge. That said, the 
first exportation carried out is that referring to the economic value of the damages displayed in the model. Such exportation, the parameters associated to the actual state of conservation of the element as well as the observations and quantifications registered will complement the information for an adequate analysis.

The code generated and executed in Dynamo to obtain a worksheet with the desired parameters was significant given the large number of parameters obtained for each family of elements as well as the large number of inspected elements. Each of the groups created was associated with an element category. The code was generated by means of the commands and functions of Dynamo as can be seen in Figure 10. First, the elements of the desired category are extracted and from that group of elements the desired parameter is obtained using the function Element.GetParameterValueByName. The chains generated with the values of the parameters of all the elements of the category will be linked to a list using the command List Create. This is shown in Figure 10.
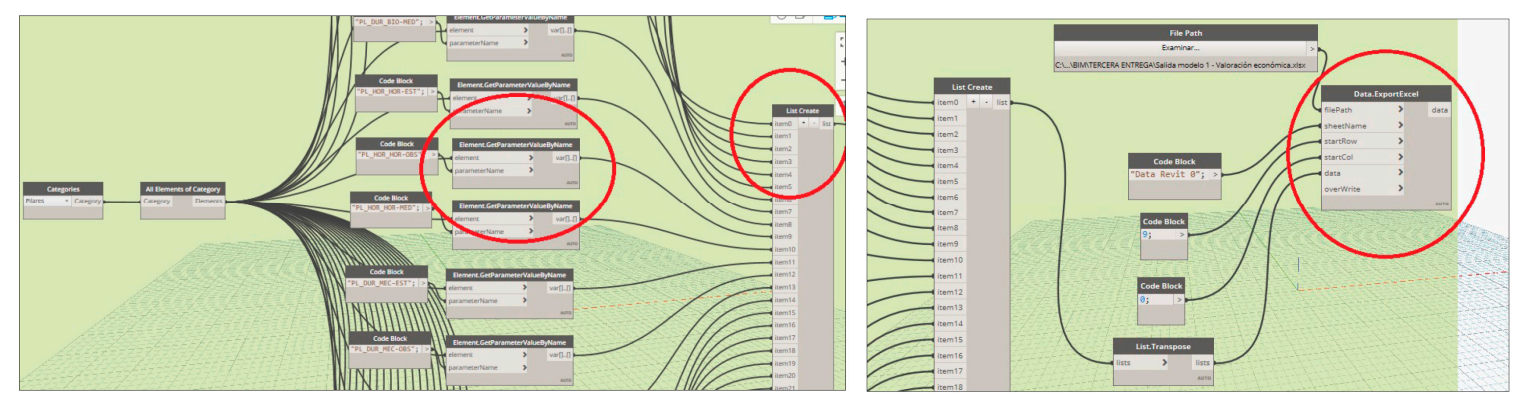

Figure 10. Detail of the extract exportation code to worksheets with id PL_DUR_SUP.

\subsubsection{Case Study 2}

BIM can also be used to avoid conflicts during bridge substitution works with no traffic interruption [25]. This implies the construction of a temporary bridge to divert the traffic, the demolition of the existing bridge and the final construction of the new bridge in the original position.

For this second case study, a bridge located over the Perales river in M-510 road in the Madrid region was used. Such structure needed to be widened in order to improve the quality of the service and the traffic safety.

The existing bridge only permits the traffic on one direction. Since the M-510 road is a two directions road, therefore the traffic is regulated through traffic lights. The project seeks to replace the bridge with a new one with two traffic lanes so that this problem can be solved. However, during the construction, the traffic should not be diverted. Moreover, the opportunity permitted including pedestrian lanes on each side given that it is currently normative.

The use of BrIM methodology will ensure the absence of interferences between the different phases of the project. To do that it is necessary to create models of the bridges and the linear works. Once the models are completed an interference analysis as a function of time can be carried out with programs like Navisworks. Civil works modeling programs such as Istram, Open Roads, Clip, or Civil3D can be used. Each one has advantages and drawbacks but all of them are tools working in the BIM methodology.

The construction works were simulated through all the constructive phases as it is shown in Figure 11. 
1 $\frac{\text { EXECUTION OF SIDE ROAD TO TRAFFIC }}{\text { DIVERTING }}$
- DEMOLITION AND TRAFFIC
PROTECTION WITH A BARRIER
$-\quad$ EXCAVATION AND FOUNDATION
WORK TO EXTEND ABUTMENTS.
EXECUTION OF LANDINGS,
BRIDGE DECK OF SIDE ROAD AND
LOCATIONS OF BEAMS

- Placement of traffic signs AND PROVISIONAL BARRIERS

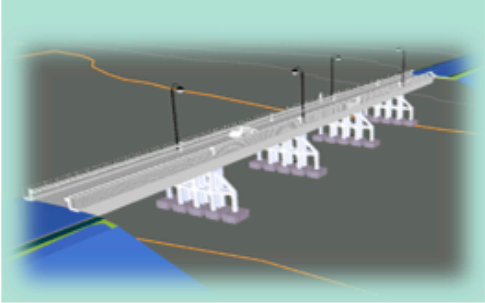

2 DEMOUTION OF THE
STRUCTURES OCCUPYING

- Parapets and GUARDRAIL REMOVAL

- Disassembly and REMOVAL OF THE EXISTING BRIDGE DECK

- Demolition of THE EXISTING PILES

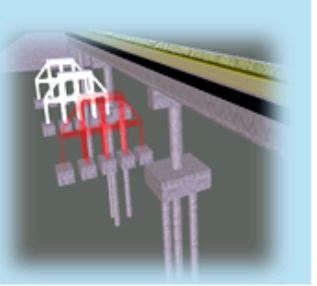

3

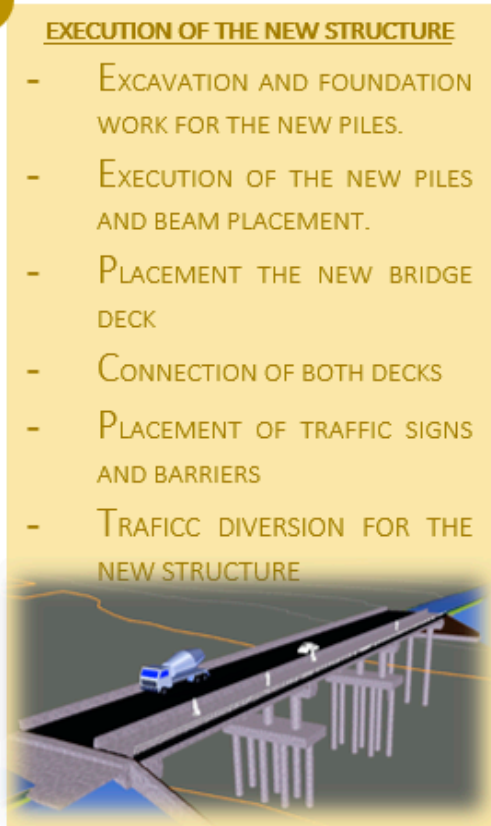

Figure 11. Phases for BrIM rehabilitation of the bridge over the Perales river.

For the old bridge modeling (Figure 12) Autodesk Revit was employed. However, due to the complexity of the columns it was necessary to turn to Inventor software for the creation of some families.

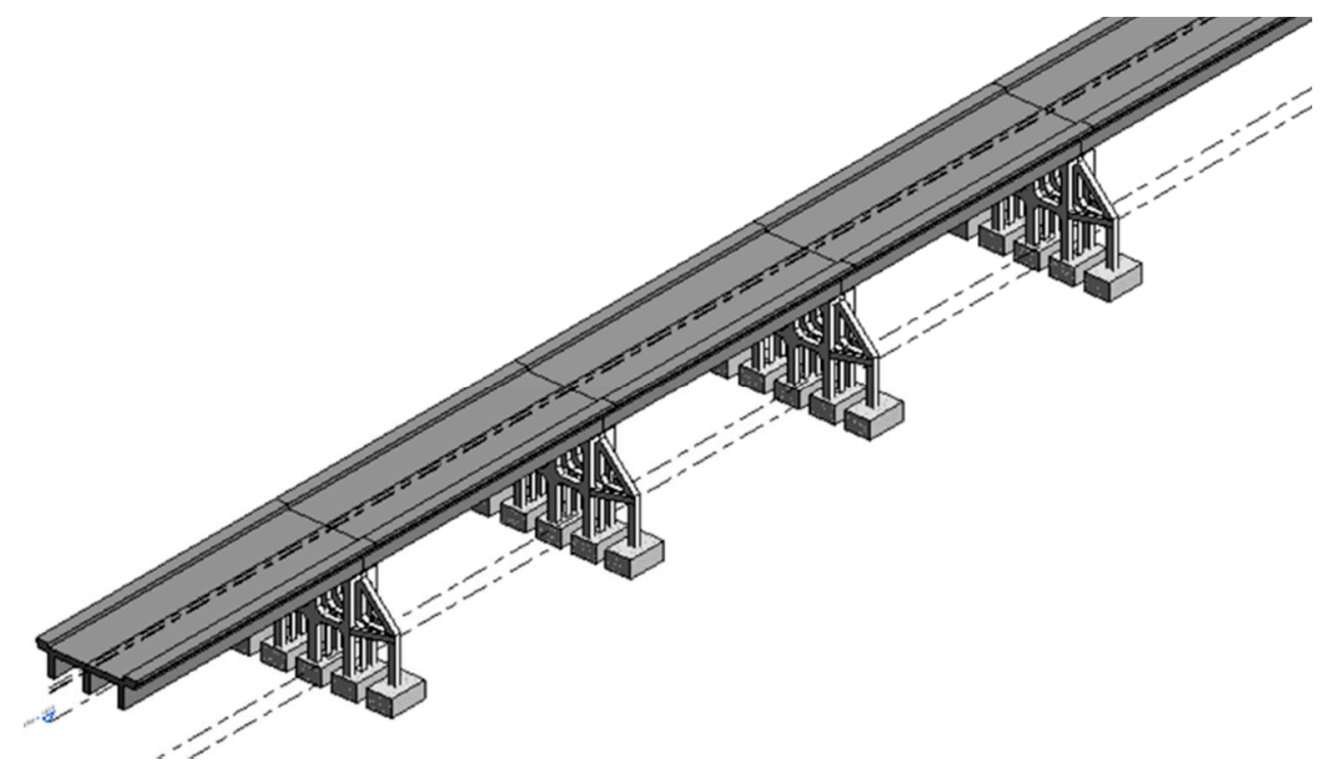

Figure 12. Graphical visualization of the old bridge.

The construction works of the new structure were defined from a general axis that coincided with the axis of the road platform. The geometrical aspect of the bridge can be seen in Figure 13. 


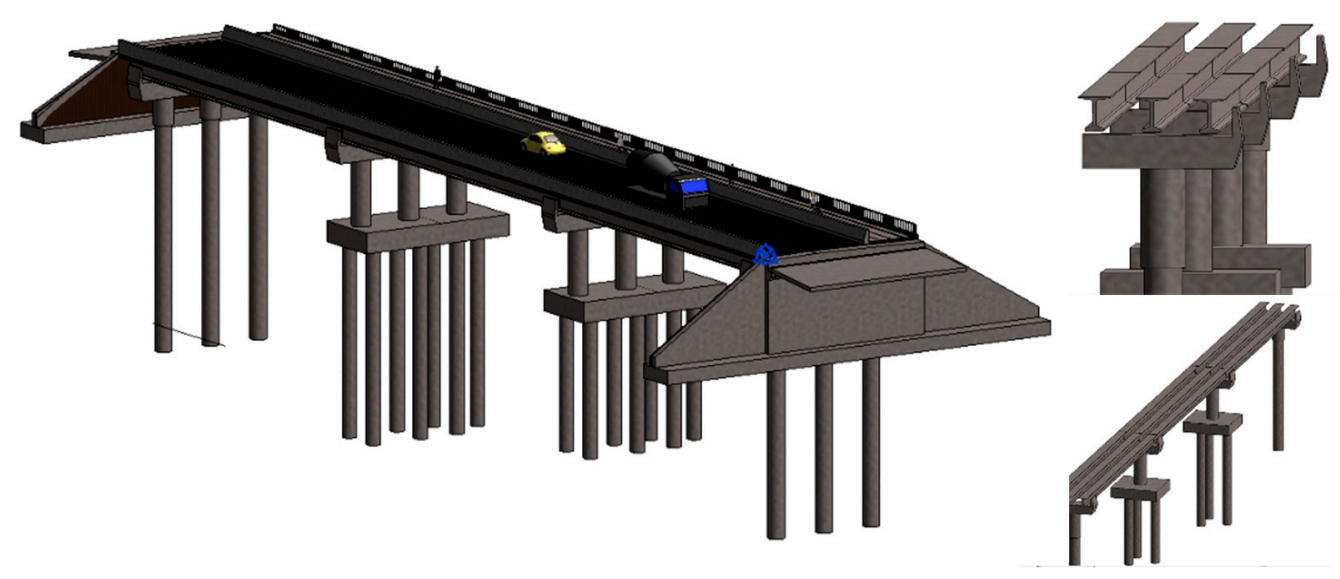

Figure 13. Graphical visualization of the new bridge.

\subsection{Roads, Tunnels, and Highways}

The transport infrastructure plays a key role in the economic and social activities for any country development. Presently most of the road projects keep using for design and construction a 2D model-based methodology in plan and elevation views with some cross sections. That makes a difficult, error prone task the checking of the required rules. Thus, new initiatives intending to improve the design, construction, and maintenance of these infrastructure elements are to be expected. In this respect the use of BIM methodology can be decisive to increase the quality of the infrastructure along their service life. With that objective a consortium of Spanish companies has launched a project called ROADBIM ITC-20161077 using state I+D+i program funds of the Spanish Government to unify criteria for road design [26]. The project's main purpose is to achieve a more efficient development of the road designs for their whole service life using BIM methodology. The great majority of the road and transport systems in Spain are public owned so that the benefits of this BIM implementation will mostly be for the government and the sector companies.

On one side, the applications of this methodology in the design and construction of linear works incorporating geographical information is a high value source to adjust the road layout according to hybrid conditions including social impacts, material proximities, etc. This way different layout alternatives can be studied in order to select the most appropriate [27] thus avoiding extra costs and construction delays. However, the adaptation of BIM methodology to the construction of linear work layouts keeps facing significant challenges. There are several previous studies trying to integrate the design and structural analysis in BIM by breaking down the layout in individual sections [28]. Nevertheless, in most cases the design cannot be made apart to the structural design because they affect the long-term performance of the layout [29]. The lack of standardization of the structural elements makes it necessary the use of different software packages because none of them ensure the integration of all requirements. As above commented, Revit is the reference software for 3D modeling including simultaneously other information. However, the capacity of this software is quite limited in high dimension linear works and the interoperability with some specific software like Infraworks or Civil $3 \mathrm{D}$ is poor. It is also needed to keep in mind that the effort required for infrastructure modeling will greatly depend on the complexity of the project and that the creation of a level of detail (LOD) with the basic information will be indispensable prior to the model construction as can be observed in Figure 1 [19].

Several stretches of the M-30 Madrid ring highway have been modeled [30] including linear works and some parts of the tunnel (Figure 14). It is one of the world's highest traffic density roads with 300,000 vehicles per day and a length of $325 \mathrm{~km}$. The goal is to develop a workflow model similar to Figure 6 for the infrastructure maintenance and to link the information of the maintenance workers with the model. 


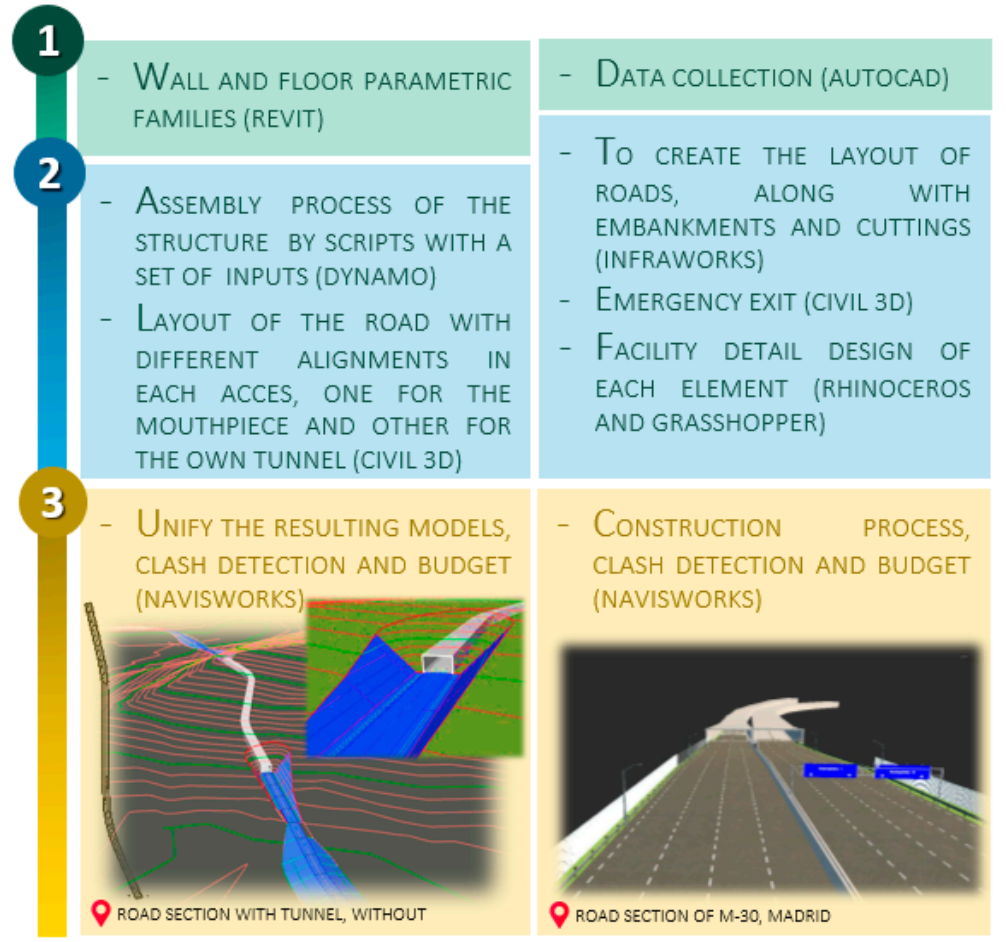

Figure 14. Design methodology of a linear work infrastructure.

In this case, for the creation of the operation and maintenance model, the Revizto program was used. Revizto is a software package for visual collaboration based on the cloud that centralize the 3D environment and is useful for problem detection. The management data was developed and is shown in Figure 15.

Civil 3D and subsequent revision with Navisworks are the most useful software for simple and efficient design of a road. In the case of a road followed by a tunnel the script was in charge of locating the parametric family. The curve is defined by coordinates in an Excel sheet (exported form a Civil3D file). Then, with the families distributed along the curve a solid is created by the unification process of the cross sections.

To allow Dynamo making of the process a series of inputs are required, mainly providing the coordinates of the tunnel points, the difference of families, and the distance step in which the families are distributed. With these data the script is able to generate a new family that covers the complete tunnel modeling.

It must be taken into account that the activities for constructing new linear works are only a small percentage of the total network and that suggests that the new efforts should concentrate in developing efficient systems of management and maintenance. Initially the information was obtained manually and later, progressively, a fleet of technology equipped vehicles was launched. In parallel, several software packages were developed to allow the fast and simple management of the site data. At this point it is necessary to use BIM models to gather the saved information, so achieving better planning and cost reductions due to the automatic transferring of the information. There are already several successful BIM applications in the design, construction, and management of linear infrastructure like the MI J33 in the United Kingdom or the enlargement of road A1 2LB between Leeming and Barton [31]. However, in all cases the authors insist in the need of improving the operability between the software packages and developing a data integration strategy in order to improve the value of the 3D model.

It is therefore necessary to obtain the geometrical definition of the road alignment in an automatic way and integrate all the management systems of the network in a single model. The detection and measuring system of objects using a Laser Imaging Detection and Ranging (LIDAR) has been a kind 
of revolutionary in the field because it can generate a big point cloud of the infrastructure with high resolution and precision [32].

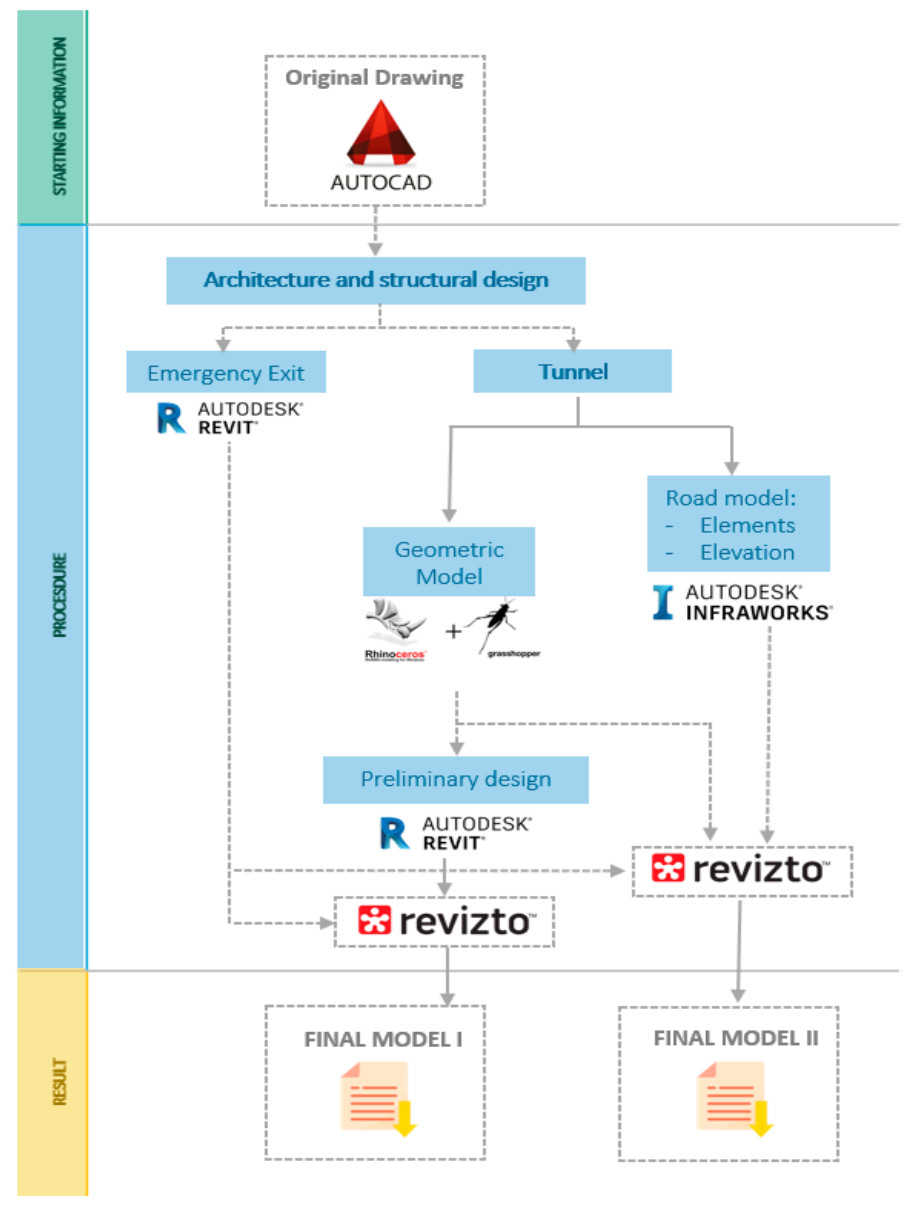

Figure 15. Proposed facility management for maintenance and exploitation of roads.

\subsubsection{Case Study 3}

The project was based on the idea of applying BIM to the conservation and exploitation of the M-513 road in the Madrid region. The high cost of the LIDAR is the main obstacle for it developing in small scale cases like the present one. Photogrammetry is in these cases an ideal substitute because it is affordable, saves time, and is able to scan large areas with reasonable precision. This way it is possible to generate a model containing: geometry, special relationship data, geographical information, quantities and properties of construction elements, and cost and inventory of materials. By the integration of all these parameters the final dimension of BIM (7D) is reached allowing the management of the whole life cycle of the project and associated services like inspections, repairing works, management, etc.

This final dimension or operational phase requires a complete, well-structured, and adapted information bank and that is why the information flow must be active with a methodology similar to the one shown in Figure 16. 


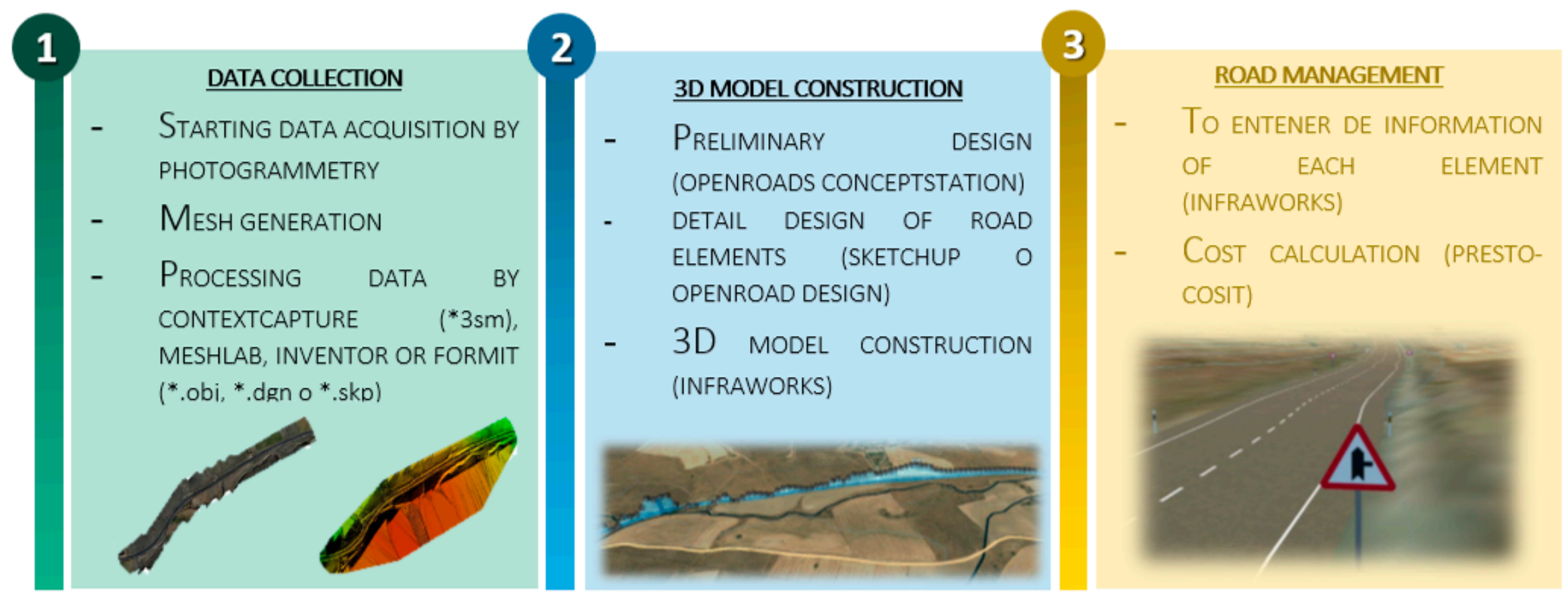

Figure 16. Methodology for the maintenance and repair road section. 
A drone Mavic-Pro M1P was employed. The surface taken and the flight routes can be seen in Figure 17.

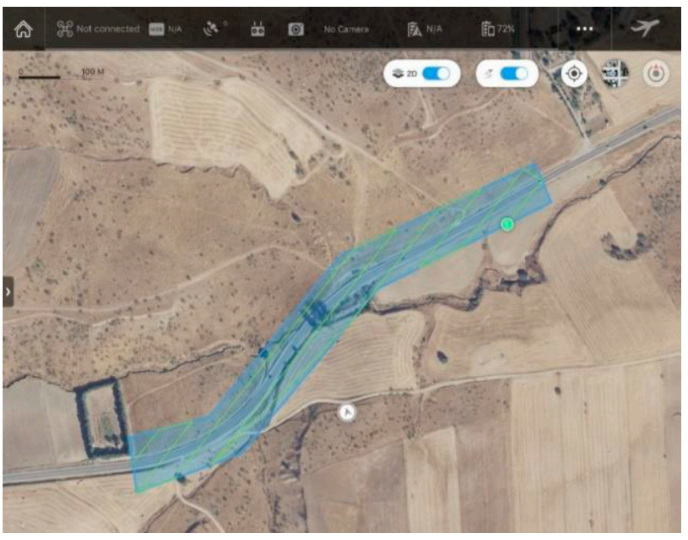

(a)

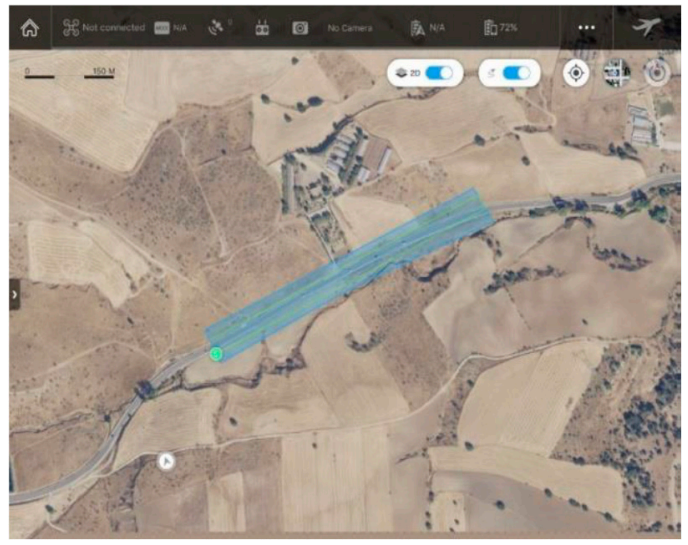

(b)

Figure 17. Different flight routes of the drone: (a) curved flight (b) straight flight

As above said, the application of the BIM methodology to road maintenance requires the previous generation of a photogrammetric grid provided by drone flying. In these cases, the operability with Revit software of Autodesk is quite limited. It is then necessary to turn to intermediate software such as Meshlab, Inventor, or FormIt that use friendly formats as *.obj, *.dgn, or *.skp although they still suffer important information losses. In these circumstances the use of OpenRoads ConceptStation of the commercial firm Bentley and ContextCapture as intermediate software are recommended. The reconstruction process used the information of the aerial triangulation to process the images and create a three-dimensional dataset. Such a dataset can be obtained as a 3D mesh, a point cloud, or raster images (see Figure 18).

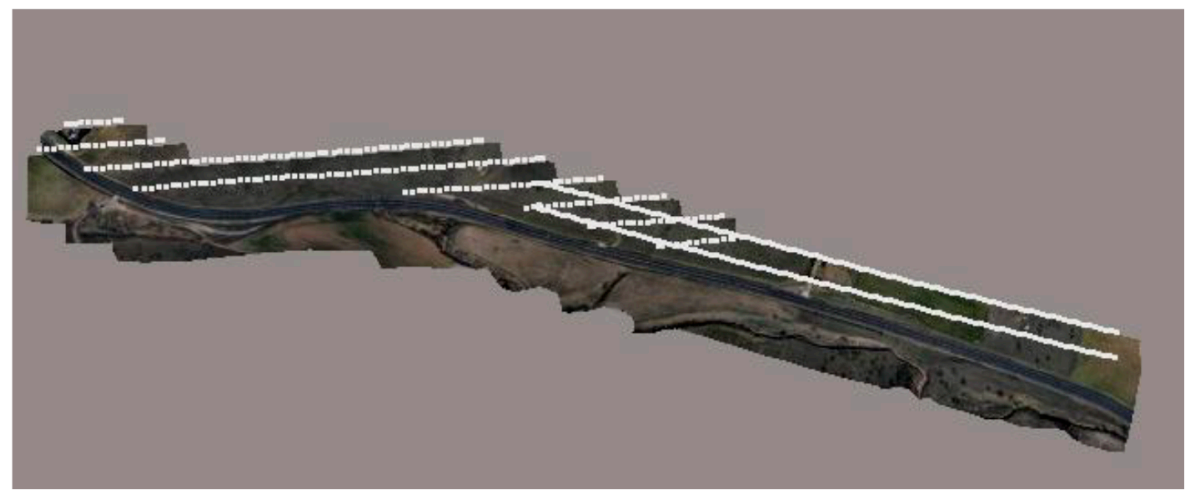

Figure 18. 3D view of the raster images with ContextCapture.

Nevertheless, to reconstruct the virtual 3D model this program shows limitations because it is oriented to preliminary studies and the use of OpenRoads Designer is required for higher detail such as road marking. To introduce the information in the elements of the road for the BIM management, AssetWise ALIM can be used. It helps improving accessibility, quality, integrity, and relevance of the active data through all the service life of the infrastructure. It allows controlling of the information, documents, and registry and managing the changes guarantying the deliver and reception of the information to the engineers and operation staff. An alternative is using Infraworks that allows including such information and with the help of SketchUP vertical elements can also be introduced.

Figure 19 shows the comparison of the reality with the model, revealing that the model was a very highly visual model and rich in information. This information could be used through facility 
management programs to manage the infrastructure, offering advantages in terms of efficiency and quality. In addition, the visual information can help the decision-making process and can reduce errors that lead to higher costs.

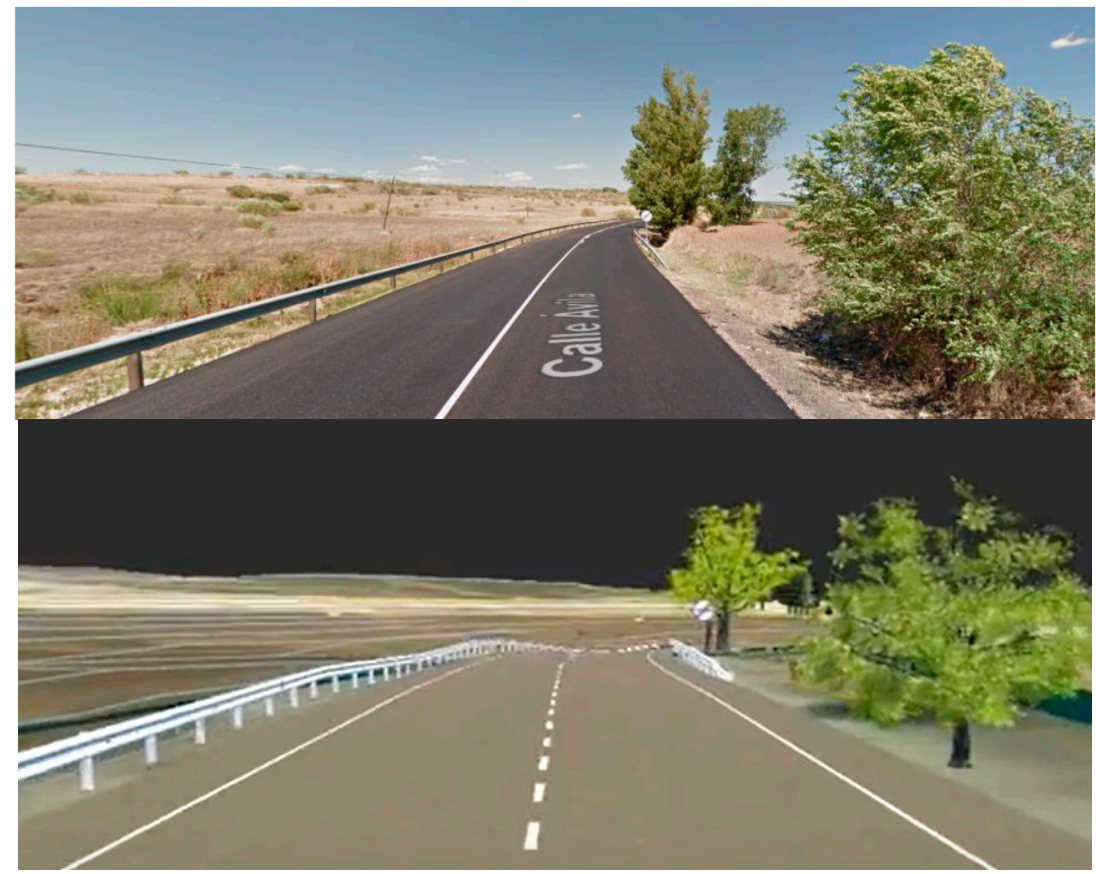

Figure 19. Comparison of the reality on top with the model below.

\subsubsection{Case Study 4}

This fourth study is about the incursion of the BIM methodology in road projects focusing on one of their fundamental aspects: the provisional deviations and the road safety of the different alternatives $[33,34]$. Due to the affectations made by the work in progress, BIM could be an efficient tool.

However, as was shown in the previous study (Figure 11), there is a lack of references about the systematization in construction. In order to achieve this objective, taking the road safety and the costs as key variables that guide the design through the different software and independent criteria, aligned in such a way that the best design could be systematically guaranteed. The project objective was to deviate the A-30 highway in Murcia, Spain. To do so, a fly-over bridge was included, and the main platform was modified as can be seen in Figure 20.

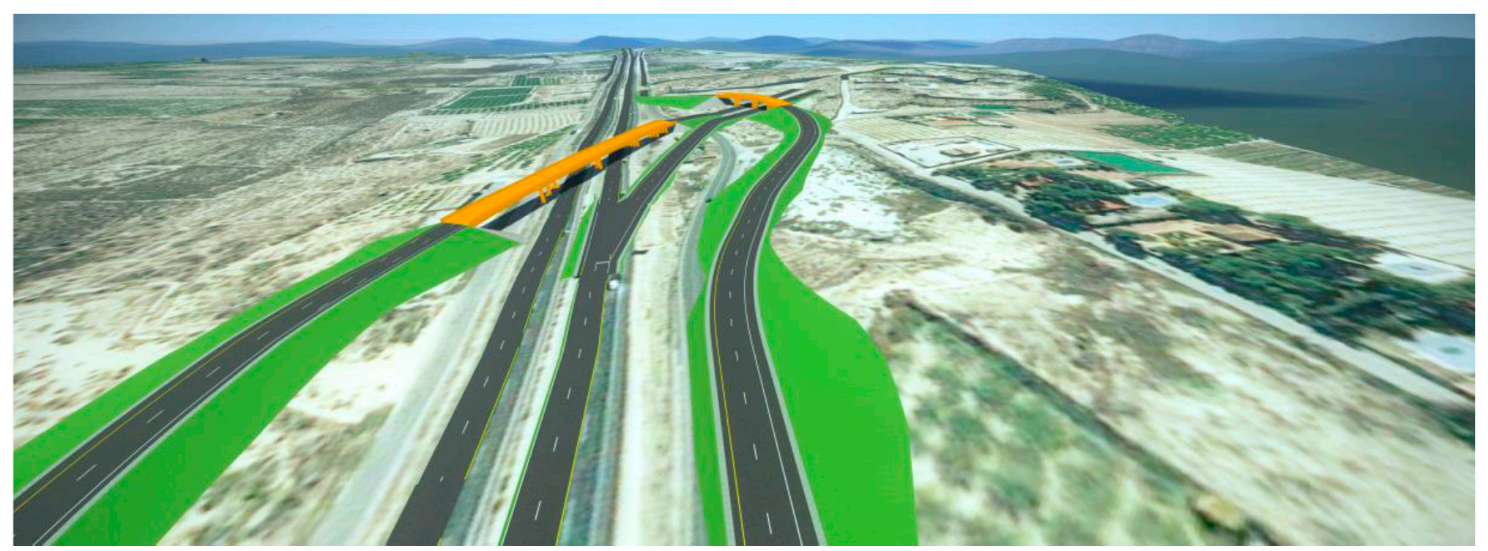

Figure 20. Graphical visualization of the modification in A-30 from ConceptStation. 
An indicator of risk (IRDO) based on hierarchical-analytical criteria was designed based on the legislation and audits reviewed in terms of road safety. It is a way to grade the deviation proposed by variables directly read from the design models.

Additionally, by using a Hasse diagram, the most important attributes: signs and beaconing have been recognized as the guarantors of the safety during the work execution. For that reason, these elements were modeled with greater detail using SketchUp, which is such a useful example of the LOD characteristic of the BIM methodology. Moreover, as a part of this higher definition, every signal includes parametric modeling, incorporating worksheets, and web directions to the technical specifications of the supplier to achieve the design suitability throughout the whole project's life.

A range of alternatives was generated for being an example of deviation using OpenRoads ConceptStation (Figure 21). The design of each alternative on a reality grid allows obtaining the quantifying variables of the program's own risk, incorporating at the same time, those coming from signaling and beaconing by importing said elements. From each one of the proposed alternative designs, a value of the construction cost and another from the IRDO was obtained.
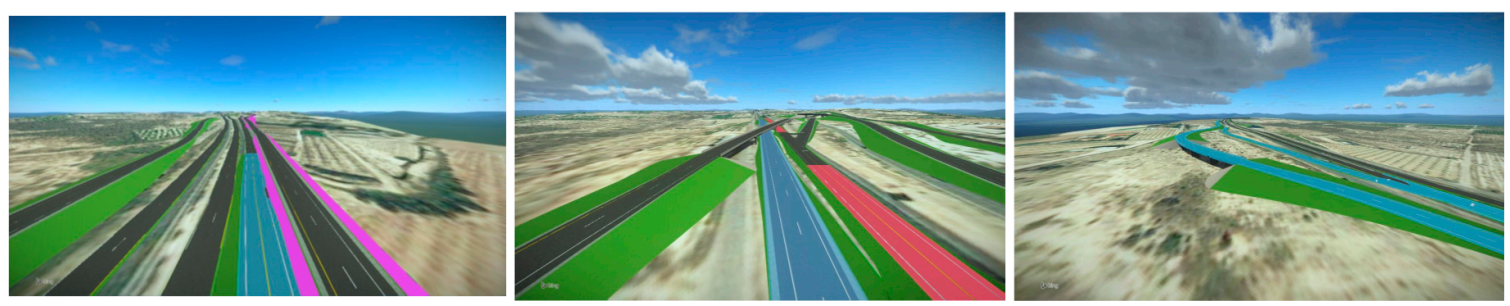

Figure 21. Three alternatives for the deviation of the A-30 highway.

The weighted valuation of the cost and the indicator was obtained (Figure 22), having more importance than the last of them. The alternative that involves the minimum risk was chosen in order to include on it the improvements carried out in a design defined and optimized.

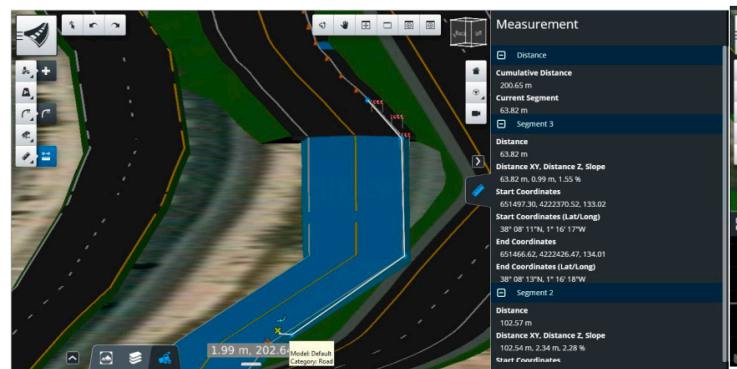

(a)

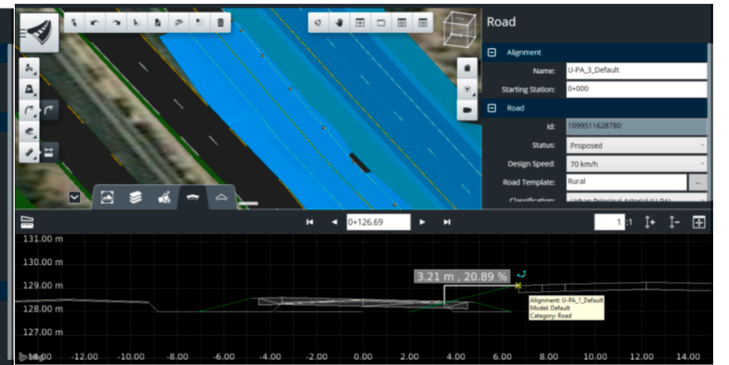

(b)

Figure 22. (a) Quantification of the risk associated to road drainage and (b) relative distance among signaling.

\section{Discussion}

In the first case study, it is shown that it is possible to develop an efficient bridge management system (BMS) that is indispensable to satisfy the massive demand of bridge maintenance activities in Spain. Previous studies have posed that bridge maintenance, mainly for historical bridges, applying this methodology for a given case [35]. However, it is worth highlighting that there are thousands of bridges at the moment that could not be considered as cultural heritage and their lifespan could reach 100 years [36,37]. BMS proposed in this study is based on BIM methodology according to real needs and using existing resources [10], and fills a blank space in the BIM standards for the maintenance and exploitation of bridges. Nevertheless, although the system is promising, it would require the 3D model 
of the existing bridges and that is why the procedure is quite limited. Additionally, the generated data should utilize Big Data technology to be useful and achieve an efficient bridge management [37].

In the second case of study, the potential use of BrIM for infrastructure replacement has been demonstrated. Navisworks has shown to be a key tool to detect interferences because it considers time as an ordinary dimension [18-39]. There are some other programs with the same possibilities such as Synchro. In this case, Navisworks was chosen because it was considered that using the software of a single commercial firm might enhance the precision of the data interchange among programs [40].

The third and fourth case studies were based on parameters that allowed gathering three-dimensional and parametric models from the 3D-scanning data. Thus, each item was linked from SketchUp to the uniform resource locator (URL) for each datasheet. This datasheet can vary and include requirements such as reflectance, service life, etc., in the tendering phase. Such features may be replaced by those supplied by the manufacturer when the real works are performed. Moreover, in both OpenRoads ConceptStation and OpenRoads Designer, it has been possible to incorporate the elements with their attributes on the program library [41]. In addition, a new table indicating element to element any aspect associated with any specific traffic sign including its location or other aspects of the construction works was included. The conclusion of this project showed the successful use of BIM for this purpose, including in the same model elements with different LOD, sequentially designed and with a final impartial value for the decision-making process [42].

The above discussion and examples reveal that in spite of the scarce implementation of BIM in active management of civil engineering constructions [6] its use is very interesting. With it a single model contains all the historical information relative to the vital elements of the roads and bridges. Respecting the available software packages and their interoperability it has been shown that the main problems with BIM usage are just the interoperability between different software packages, especially if they are supported by different firms [43].

Through use of a combination of software and some programming, the case studies reveal the outstanding possibilities of the use of BIM for the maintenance and exploitation of important existing infrastructure. In addition, it has shown that it helps studying the work schedule and program of the construction works in order to maintain the service during the execution of rehabilitation works [44]. Moreover, the use of digital tools and BIM can help assessing the best alternative in terms of safety [45]. The results have shown that BIM helps the decision-making processes of the managing staff as well as diminish the risk of errors.

Regarding the augmented reality, photogrammetry is a method able to produce models of precision similar to the point clouds [46] when the resolution of the captured image is high enough because the deviation will be in the range of two pixels. In these cases, it is a suitable methodology for research, documentation, and environment characterization and is faster and less expensive compared to the sophisticated and hardly operable LIDAR equipment. This way a grid texture with simple visual interpretation is generated, also including real shapes and information relative to the existing conditions that can be more easily analyzed by the above-mentioned programs.

\section{Conclusions}

The aging and deterioration of transport infrastructure is a problem of most importance that consumes high annual budgets due to the huge infrastructure patrimonies of all countries. The high increase of road construction makes it insufficient and inefficient the traditional existing management and inspection systems. In this paper some successful examples in which the BIM methodology produced optimum and sustainable infrastructure management have been presented. Additionally, maintenance cost reductions were obtained.

However, the application of BIM methodology in infrastructure is still quite complex. The great impediment to the implementation of BIM in the management and maintenance of infrastructure is the lack of specialized software. Currently, the existing infrastructure design software is not capable of being used as BIM models. The most used infrastructure programs Civil 3D or OpenRoadsDesigner, 
only allow the creation of 2D or 3D models of surfaces, but it is not possible to create all the elements with their own characteristics that allow reflecting the particularities and differences between the different elements. This means, that they are empty geometrical elements, so they are not really BIM models. Moreover, the most used BIM design programs (Revit) are not adapted to the design of infrastructure. These architectural design programs have been created to design vertical elements defined in different horizontal levels (floors), so it does not allow one to work in a simple way with structures with a large horizontal extension. It would be very interesting, if future developments could add some tool that would allow generating alignments as reference elements or vertical levels, to subdivide the linear infrastructure. In this way it would be possible to work with this type of infrastructure software packages.

There is also a series of programs recently available, which allow the design of infrastructure in a 3D environment, with parameterisable elements as Infraworks or Openroads Conceptstation. These types of programs are much closer to the concept of BIM for infrastructure and are very interesting tools. Unfortunately, although these programs allow the 3D visualization of projects in their environment easily and quickly, they still lack many functionalities required to be implemented in a BIM-FM model. One major problem with these programs is the impossibility of exporting 3D models.

It can then be stated that, although BIM is not yet implemented as an active management tool in the great majority of infrastructure projects, a successful and promising future for it is to be expected. With this technology important advantages are achieved in the design, construction, maintenance, and rehabilitation of infrastructure elements with the additional feature of having different working alternatives in the design process.

In short, it could be said that BIM is already a reality and, although today its use is more related to the civil engineering industry, the complete introduction of this methodology in the design of roads, highways, tunnels, or bridges is only a matter of time.

Author Contributions: Conceptualization, M.G.A. and A.A.Á.; Data curation, Á.M.B. and A.A.Á.; Formal analysis, M.G.A.; Investigation, Á.M.B.; Methodology, M.G.A. and A.A.Á.; Project administration, M.G.A.; Resources, M.G.A.; Software, Á.M.B., J.A.T. and A.A.Á.; Supervision, M.G.A.; Validation, A.A.Á.; Writing-original draft, Á.M.B. and M.G.A.; Writing-review \& editing, M.G.A. and J.A.T. All authors have read and agreed to the published version of the manuscript.

Funding: This research received no external funding.

Acknowledgments: The authors gratefully acknowledge the financial support provided by the Ministry of Economy, Industry and Competitiveness of Spain by means of the Research Fund Project PID2019-108978RB-C31. They also offer their gratitude to Calle 30 for supporting the Enterprise University Chair Calle30-UPM. Authors also acknowledge the support provided by the UPM through the Educational Innovation Project IE1920.0409.

Conflicts of Interest: The authors declare no conflict of interest.

\section{References}

1. Pham, C.; Iyer, S. The business value of BIM for construction in major global markets: How contractors around the world are driving innovation with building information modeling. In Smart Market Report; McGraw Hill Construction: Bedford, UK, 2014; pp. 1-60.

2. Jung, W.; Lee, G. The status of BIM adoption on six continents. Int. J. Civ. Environ. Struct. Constr. Archit. Eng. 2015, 9, 444-448.

3. Lee, N.; Dossick, C.S. AC 2012-4816: Leveraging Building Information Modeling Technology in Construction Engineering and Management Education. In Proceedings of the Annual Conference of the American Society for Engineering Education, San Antonio, TX, USA, 10-13 June 2012.

4. Ju, K.B.; Seo, M.B. A study on the issue analysis for the application of BIM technology to civil engineering in Korea. Creat. Educ. 2012, 3, 21-24. [CrossRef]

5. Jones, S.; Laquidara-Carr, D.; Lorenz, A.; Buckley, B.; Barnett, S. The business value of BIM for infrastructure 2017. In SmartMarket Report; Dodge Data \& Analytics: Bedford, UK, 2017. 
6. Costin, A.; Adibfar, A.; Hu, H.; Chen, S.S. Building Information Modeling (BIM) for transportation infrastructure-Literature review, applications, challenges, and recommendations. Autom. Constr. 2018, 94, 257-281. [CrossRef]

7. Sadeghi, H.; Mohandes, S.R.; Hamid, A.R.A.; Preece, C.; Hedayati, A.; Singh, B. Reviewing the usefulness of BIM adoption in improving safety environment of construction projects. J. Teknol. 2016, 78, 10. [CrossRef]

8. Muriel, A.P.P.; Rodríguez, A.M.R. BIM como paradigma de la modernización del flujo de trabajo en el sector de la construcción. Span. J. Build. Inf. Model. 2015, 15, 36-45.

9. Hudson, R.W.; Carmichael, R.F., III; Hudson, S.W.; Diaz, M.A.; Moser, L.O. Microcomputer bridge management system. J. Transp. Eng. 1993, 119, 59-76. [CrossRef]

10. Red de Carreteras del Estado. Guía para la realización del inventario de obras de paso. In Centro de Publicaciones; Secretaría General Técnica, Ministerio de Fomento, Gobierno de España: Madrid, Spain, 2009.

11. Cañamares, J.M.; Suárez, M.Á.A. Sistemas de Gestión de Puentes Optimización de Estrategias de Mantenimiento Implementación en Redes Locales de Carreteras. Ph.D. Thesis, Universidad Politécnica de Madrid, Madrid, Spain, 2016.

12. Wan, C.; Zhou, Z.; Li, S.; Ding, Y.; Xu, Z.; Yang, Z.; Yin, F. Development of a Bridge Management System Based on the Building Information Modeling Technology. Sustainability 2019, 11, 4583. [CrossRef]

13. MacLeamy, P. BIM, BAM, BOOM! How to Build Greener, High-Performance Buildings. Urban Land Green Magazine. 2008. Available online: https://www.archdaily.com/262008/the-future-of-the-building-industrybim-bam-boom (accessed on 10 October 2020).

14. Gao, J.; Martin, F. Framework and Case Studies Comparing Implementations and Impacts of 3D/4D Modeling Across Projects; Stanford University: Stanford, CA, USA, 2008.

15. Zou, Y.; Zhou, S.X. A Model-Based BIM Framework for Bridge Engineering. In Applied Mechanics and Materials; 587; Trans Tech Publications Ltd.: Stafa-Zurich, Switzerland, 2014; pp. 1339-1343.

16. Cheng, J.C.P.; Lu, Q.; Deng, Y. Analytical review and evaluation of civil information modeling. Autom. Constr. 2016, 67, 31-47. [CrossRef]

17. Lee, S.H.; Park, S.I.; Park, J.; Seo, K.W. Open BIM-based information modeling of railway bridges and its application concept. Comput. Civ. Build. Eng. 2014, 504-511. [CrossRef]

18. Zou, Y.; Kiviniemi, A.; Jones, S.W.; Walsh, J. Risk information management for bridges by integrating risk breakdown structure into 3D/4D BIM. KSCE J. Civ. Eng. 2019, 23, 467-480. [CrossRef]

19. Sankaran, B.; France-Mensah, J.; O’Brien, W.J. Data Integration Challenges for CIM in Large Infrastructure: A Case Study of Dallas Horseshoe Project. In Proceedings of the 16th International Conference on Computing in Civil and Building Engineering, Osaka, Japan, 6-8 July 2016.

20. Blanco Rávena, R.; Martínez García, J.; Mozas González, B.; García Alberti, M.; Arcos Álvarez, A.A. Use of BIM methodology in the re-modelling of an existing bridge. An. Edif. 2019, 5, 100-106.

21. Haardt, P. Development of a bridge management system for the German highway network. In Proceedings of the First International Conference on Bridge Maintenance, Safety and Management, Barcelona, Spain, 14-17 July 2002.

22. McGuire, B.; Atadero, R.; Clevenger, C.; Ozbek, M. Bridge information modeling for inspection and evaluation. J. Bridge Eng. 2016, 21, 04015076. [CrossRef]

23. Shim, C.S.; Kang, H.R.; Dang, N.S.; Lee, D.K. Development of BIM-based bridge maintenance system for cable-stayed bridges. Smart Struct. Syst. 2017, 20, 697-708.

24. Cuenca Martínez, A.J.; Díaz Margarit, A.; Hernando Fernández, E.; Alberti, M.G.; Arcos Álvarez, A.A. Implementation of BIM methodology into the conservation and maintenance of bridges. In Proceedings of the V International Conference on Technological Innovation in Building, Madrid, Spain, 25 March-8 April 2020.

25. Arcos González, A.; Bueno Leal, P.; Bermeosolo Echeverría, L.; Alberti, M.G.; Arcos Álvarez, A.A. BIM methodology for the extension of an existing bridge. In Proceedings of the $\mathrm{V}$ International Conference on Technological Innovation in Building, Madrid, Spain, 25 March-8 April 2020.

26. Moya Sala, Q.; García García, A.; Camacho-Torregrosa, F.J.; Campoy Ungria, J.M. BIM para infraestructuras de carreteras: Verificación de la normativa de diseño geométrico. Span. J. BIM 2017, 17, 10-18.

27. Kim, H.; Orr, K.; Shen, Z.; Moon, H.; Ju, K.; Choi, W. Highway alignment construction comparison using object-oriented 3D visualization modeling. J. Constr. Eng. Manag. 2014, 140, 05014008. [CrossRef] 
28. Li, X.; Tian, Y.; Tian, L.; Chen, S.; Wang, A. Multiscale BIM modeling and adaptive splicing method of mountain tunnel structure for engineering application. China J. Highw. Transp. 2019, 32, 126.

29. Tang, F.; Ma, T.; Zhang, J.; Guan, Y.; Chen, L. Integrating three-dimensional road design and pavement structure analysis based on BIM. Autom. Constr. 2020, 113, 103152. [CrossRef]

30. Pastor Moreno, D. BIM Methodology Application for the Operation and Maintenance of the M-30 Road. Master's Thesis, Universidad Politécnica de Madrid, Madrid, Spain, 2019.

31. Zhu, J.; Chen, Z.; Sun, L.J. A method of construction of index system for highway maintenance management. Procedia Soc. Behav. Sci. 2013, 96, 1593-1602. [CrossRef]

32. Omoregie, A.; Turnbull, D.E. Highway infrastructure and building information modelling in UK. In Proceedings of the Institution of Civil Engineers-Municipal Engineer; Thomas Telford Ltd.: London, UK, 2016; pp. 220-232.

33. Reeder, G.D.; Nelson, G.A. 3D Engineered Models for Highway Construction: The Iowa Experience; National Concrete Pavement Technology Center, Iowa State University: Ames, IA, USA, 2015.

34. Rodríguez Gámiz, J.A. Sistematización para la Aplicación Práctica de Desvíos Provisionales en Obras de Carretera Aplicando Metodología BIM y Criterios Jerárquico-Analíticos Para la Cuantificación de la Seguridad Viaria. Master's Thesis, Universidad Politécnica de Madrid, Madrid, Spain, 2019.

35. León-Robles, C.A.; Reinoso-Gordo, J.F.; González-Quiñones, J.J. Heritage building information modeling (H-BIM) applied to a stone bridge. ISPRS Int. J. Geo-Inf. 2019, 8, 121. [CrossRef]

36. Spanish Ministry of Public Works. EHE-08 Instrucción del Hormigón Estructural; Secretaría General Técnica, Ministerio de Fomento, Gobierno de España: Madrid, Spain, 2008.

37. Navarro, I.J.; Martí, J.V.; Yepes, V. Reliability-based maintenance optimization of corrosion preventive designs under a life cycle perspective. Environ. Impact Assess. Rev. 2019, 74, 23-34. [CrossRef]

38. Shayganmehr, M.; Saghatforoush, E. An assessment on the parallel impacts of building information modeling and big data on project operation and maintenance. MATEC Web Conf. 2019, 276, 02002. [CrossRef]

39. Jeong, S.; Hou, R.; Lynch, J.P.; Sohn, H.; Law, K.H. An information modeling framework for bridge monitoring. Adv. Eng. Softw. 2017, 114, 11-31. [CrossRef]

40. Kaewunruen, S.; Sresakoolchai, J.; Zhou, Z. Sustainability-Based Lifecycle Management for Bridge Infrastructure Using 6D BIM. Sustainability 2020, 12, 2436. [CrossRef]

41. Abbondati, F. Rural Road Reverse Engineering Using BIM: An Italian Case Study. Environmental Engineering. In Proceedings of the 11th International Conference "Environmental Engineering", Muttenz, Switzerland, 8-10 September 2020.

42. Biancardo, S.A.; Viscione, N.; Cerbone, A.; Dessì, E. BIM-Based Design for Road Infrastructure: A Critical Focus on Modeling Guardrails and Retaining Walls. Infrastructures 2020, 5, 59. [CrossRef]

43. Djuedja, J.F.T.; Karray, M.H.; Foguem, B.K.; Magniont, C.; Abanda, F.H. Interoperability challenges in building information modelling (BIM). In Enterprise Interoperability VIII; Springer: Cham, Switzerland, 2019; pp. 275-282.

44. Silva, M.J.F.; Couto, P.; Pinho, F.; Lopes, J. Building Functional Rehabilitation Based on BIM Methodology. In Sustainability and Automation in Smart Constructions; Springer: Cham, Switzerland, 2019; pp. 45-49.

45. Kim, K.; Cho, Y.; Zhang, S. Integrating work sequences and temporary structures into safety planning: Automated scaffolding-related safety hazard identification and prevention in BIM. Autom. Constr. 2016, 70, 128-142. [CrossRef]

46. Rizo-Maestre, C.; González-Avilés, Á.; Galiano-Garrigós, A.; Andújar-Montoya, M.D.; Puchol-García, J.A. UAV BIM: Incorporation of Photogrammetric Techniques in Architectural Projects with Building Information Modeling versus Classical Work Processes+. Remote. Sens. 2020, 12, 2329. [CrossRef]

(C) 2020 by the authors. Licensee MDPI, Basel, Switzerland. This article is an open access article distributed under the terms and conditions of the Creative Commons Attribution (CC BY) license (http://creativecommons.org/licenses/by/4.0/). 